\title{
Pathophysiology of Minimally Invasive Surgical Approaches: Current Concepts
}

\author{
${ }^{1}$ Department of Orthopaedic Surgery, University of Illinois at Chicago, \\ Chicago, Illinois, United States \\ ${ }^{2}$ Department of Orthopaedics, Pediatric Orthopaedics and \\ Traumatology, The Centre of Postgraduate Medical Education, \\ Warsaw, Poland \\ ${ }^{3}$ Spine Disorders Unit, Department of Pediatric Orthopedics and \\ Traumatology, University of Medical Sciences in Poznan, \\ Poznan, Poland \\ ${ }^{4}$ Department of Neurosurgery, University of Rzeszow, Tarnow, Poland
}

Kris Siemionow ${ }^{1}$ Marcin Tyrakowski ${ }^{1,2}$ Piotr Janusz ${ }^{1,3} \quad$ Andrzej Maciejczak ${ }^{4}$

Address for correspondence Kris Siemionow, MD, Department of Orthopaedic Surgery, 835 S. Wolcott Avenue, Room E-270, Chicago, Illinois 60612, United States (e-mail: siemiok@gmail.com).

J Neurol Surg A 2016;77:326-332.

\begin{abstract}
Keywords

- minimally invasive spine surgery

- multifidus muscle

- minimally disruptive spine surgery

Spine surgery is a continuously evolving field. Traditional posterior midline approaches to the lumbar spine are associated with muscle injury. Common mechanisms of injury include ischemia, denervation, and mechanical disruption of tendinous attachments of lumbar muscles. Muscle injury may be documented with chemical markers (creatinine kinase, aldolase, proinflammatory cytokines), by imaging studies, or with muscle biopsy. Minimally disruptive surgical approaches to the spine have the potential to minimize the trauma to muscular structures and thus improve the outcomes of surgery. The impact of minimally invasive spinal surgery on long-term clinical outcomes remains unknown. State-of-the-art pathophysiology of minimally invasive spine surgery is presented in this review.
\end{abstract}

\section{Introduction}

Spine surgery is a continuously evolving field. The last decade has witnessed the development of less invasive surgical techniques. Advances in navigation, tissue retractors, and other specialized instruments have enabled surgeons to perform decompressions, and even fusions, through smaller incisions, with less disruption of muscle and soft tissue. It is important to note that the goals of decompression and stabilization are accomplished with minimally disruptive surgery. A growing body of literature is demonstrating the physiologic advantages of less disruptive surgery. This article reviews key biological concepts that support this surgical approach.

\section{Anatomy}

The basic concept behind all minimally disruptive approaches is the reduction of trauma to paraspinal muscle groups. The posterior paraspinal muscles are composed of two groups: the deep paramedian transversospinalis muscle group, which includes the multifidus, interspinalis, intertransversus, and short rotators, and the superficial and lateral erector spinae muscles (longissimus and iliocostalis) (-Fig. 1). These muscles span the thoracolumbar spine and insert distally onto the sacrum, the sacroiliac joint, and the iliac wing. In contrast to other paraspinal muscles, the multifidus muscle has a large physiologic cross-sectional area (PCSA) and short fibers. As a result of its unique structure, the multifidus muscle is designed to create large forces over relatively short distances, making it a major posterior stabilizer of the spine. $^{1-8}$

It is important to note that the multifidus sarcomere is positioned along the ascending portion of the length-tension curve. As a result of this fiber arrangement, the multifidus muscle is able to produce more force as the spine flexes received

June 26, 2013

accepted after revision

April 24, 2015

published online

August 20, 2015 (c) 2016 Georg Thieme Verlag KG Stuttgart · New York
DOI http://dx.doi.org/ 10.1055/s-0035-1558420. ISSN 2193-6315. 


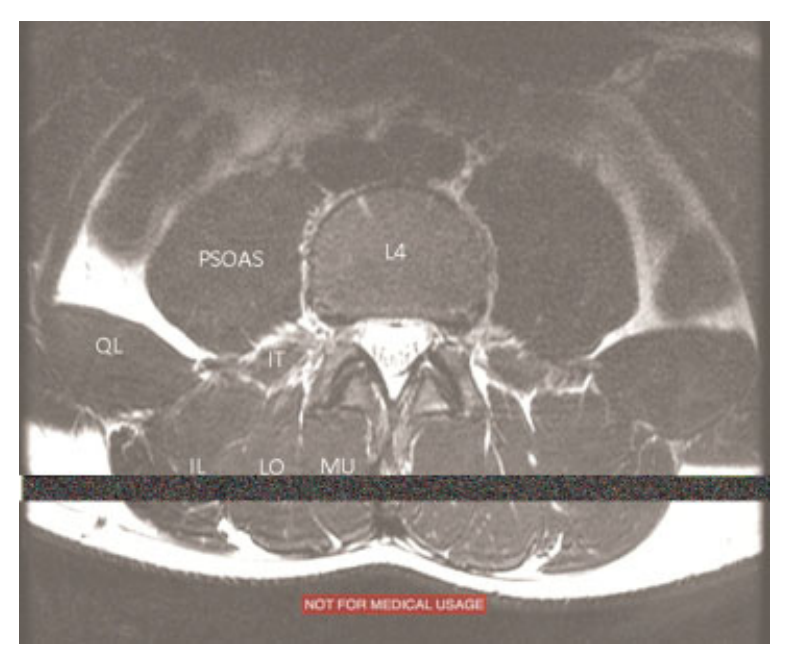

Fig. 1 Axial T-2 weighted magnetic resonance image at the L4 vertebral body level showing the psoas (PSOAS), the multifidus (MU), iliocostalis (IL), longissimus (LO), quadratus lumborum (QL), and intertransversarii (IT) muscles.

forward, protecting the spine when it is in the most vulnerable position. The morphology of the multifidus muscle is complex, and unlike other paraspinal muscles, which have specific origins and insertions, the multifidus muscle is formed by five separate bands. ${ }^{9}$ Each band is composed of several fascicles arising from the tip of the spinous process and the lateral surface of the vertebral lamina. As one proceeds caudally, the various fascicles diverge into separate attachments on the mamillary processes of the caudal vertebrae, two to five levels below their origin. The deepest fibers of the multifidus muscle are thought to provide segmental stabilization of the lumbar spine. ${ }^{10,11}$

The erector spinae muscles are composed of the longissimus, the iliocostalis, and the spinalis., ${ }^{5,12,13}$ In the lumbar spine, the longissimus muscle is positioned lateral to the multifidus muscle and originates from the transverse and accessory processes and inserts caudally into the ventral surface of the posterior superior iliac spine. The iliocostalis muscle is lateral to the longissimus muscle and originates from the tip of the transverse processes and the adjacent middle layer of the thoracolumbar fascia and inserts into the ventral edge of the iliac crest caudally. ${ }^{12,14}$ In contrast to the multifidus muscle, microarchitectural studies reveal that the iliocostalis and longissimus muscles contain long muscle fascicles with a relatively small PCSA. This anatomical arrangement suggests that they serve to move the trunk in extension, lateral bending, and rotation. They are more likely to act as secondary stabilizers of the spinal column. ${ }^{15}$

\section{Paraspinal Muscle Injury during Posterior Spinal Surgery}

Traditional posterior midline approaches to the lumbar spine result in muscle atrophy. ${ }^{4,7,16-24}$ The multifidus muscle is the most likely muscle to be injured during the standard posterior approach to the lumbar spine. Atrophy, marked by a decrease in the muscle cross-sectional area (CSA), in turn leads to decreased force production capacity of the muscle; certainly these changes are not without consequence. ${ }^{25,26}$

Glycerol is an important component of glycerophospholipid, the basic structural component of the cell plasma membrane. When the integrity of the cell membrane is disrupted, glycerol is released into the interstitial fluid. Ren et al demonstrated increased glycerol concentrations in the paraspinal muscles of patients undergoing instrumented posterolateral lumbar fusions when compared with glycerol concentrations in the patients' unoperated deltoid muscles, which served as a control. ${ }^{27}$

Kim et al studied markers of tissue injury in the blood of patients undergoing open versus minimally invasive fusions. ${ }^{28}$ Markers of skeletal muscle injury (creatinine kinase, aldolase), proinflammatory cytokines (interleukin [IL]-6, IL8), and anti-inflammatory cytokines (IL-10, IL-1 receptor antagonist) were found to be elevated several fold in patients undergoing open surgery. Most markers in the minimally invasive fusion group returned to baseline by 3 days, whereas patients in the open surgery group required 7 days.

Muscle biopsies obtained from patients undergoing revision spinal surgery have shown selective type II fiber atrophy, widespread fiber type grouping (a sign of reinnervation), and a moth-eaten appearance of muscle fibers. ${ }^{29}$

Several mechanisms are responsible for iatrogenic muscle injury. Self-retaining retractors are a common cause of muscle injury. They have a tourniquet effect on the muscle and result in local ischemia followed by reperfusion injury. ${ }^{30-32}$ Self-retaining retractors cause elevated tissue pressures that result in decreased intramuscular perfusion. ${ }^{33,34}$ The severity of the muscle injury is directly proportional to the degree of the intramuscular pressure and the length of retraction time.

Application of tubular retractors through a limited approach reduces crush injury observed with self-retaining retractors. $^{35}$ To our knowledge, no published studies have directly compared paraspinal muscles pressure after application of a tubular versus a self-retaining retractor. The superiority of tubular retractors may be anticipated based on better early clinical outcomes. ${ }^{36-40}$ However, better outcomes are not only results of the difference in pressure exerted on the paraspinal muscles by the retractors, but they are also a result of their approach-related features such as avoiding detachment of the musculotendinous complex from the vertebrae and the reduced likelihood of injuring the neurovascular bundles. $^{35,36}$

The next proposed mechanism of iatrogenic injury occurs during dissection of the multifidus muscle in conventional posterior lumbar procedures. Cutting of the tendinous origin on the spinous process may destroy the physiologic binding between muscle fibers and bone, and healing of the muscle to the bone may be affected postoperatively. ${ }^{4}$ Destroying the internal vasculature and tissue structure of this muscle during exposure may also cause ischemic necrosis of the multifidus muscle. Resection of the dorsal vertebral bony structures (spinous process, lamina) for posterior decompression of the nerves compromises the bony insertion and separation of bilateral multifidus muscles and changes its physiologic function postoperatively. ${ }^{35}$ 
Another mechanism leading to muscle degeneration and atrophy following surgery is muscle denervation. The innervation of the multifidus muscle is monosegmental, making it especially vulnerable to injury. ${ }^{9}$ The multifidus muscle is innervated by the medial branch nerve that originates from the dorsal rami of each of the lumbar spinal nerves. ${ }^{41}$ Damage to the neuromuscular junction following prolonged muscle retraction can also lead to muscle denervation. Because the medial branch nerve passes near the mamillary process, it is at risk when using traditional pedicle screw insertion techniques. ${ }^{42}$ Regev et al compared the risk of transecting the medial branch nerve after pedicle screw insertion using miniopen versus percutaneous minimally invasive techniques. ${ }^{42}$ Medial branch nerve transection was observed in $84 \%$ of cases when the pedicles were instrumented using the mini-open technique and in $20 \%$ when the percutaneous insertion technique was used. Muscle biopsies in patients diagnosed with failed back syndrome showed signs of advanced chronic denervation consisting of group atrophy, marked fibrosis, and fatty infiltration. ${ }^{43}$

\section{Application of Minimally Disruptive Techniques to Preserve Spinal Function}

Strategies used during minimally disruptive surgery result in less muscle trauma, avoid disruption of tendinous attachments, and minimize damage to the neurovascular supply. Kim et al compared lumbar muscle strength between patients treated with open posterior instrumentation versus percutaneous instrumentation. ${ }^{44}$ Patients undergoing percutaneous instrumentation displayed $>50 \%$ improvement in lumbar extension strength, whereas patients undergoing open surgery had no significant improvement in lumbar extension strength.

Stevens et al used magnetic resonance imaging (MRI) to analyze the postsurgical appearance of the multifidus muscle. ${ }^{45}$ In patients treated with a traditional open posterior transforaminal lumbar interbody fusion (TLIF) technique, marked intermuscular edema was observed on MRI at 6 months postoperatively. In contrast, patients in the miniopen TLIF group had a normal multifidus muscle appearance on MRI at 6 months following surgery. Tsutsumimoto et al demonstrated that multifidus muscle atrophy and T2 signal intensity on MRI after mini-open PLIF were significantly lower than those observed in patients following an open PLIF. There was no difference in Japanese Orthopedic Association scores between the two groups. ${ }^{46}$ Wang et al showed that the MRI T2 relaxation time of the multifidus muscles was significantly shorter in patients who underwent minimally invasive TLIF versus patients who had open TLIF 3 months postoperatively. ${ }^{47}$ The electromyographic examination revealed that the average discharge amplitude and frequency of the sacrospinalis muscle were significantly higher in minimally invasive surgery (MIS). Clinical outcomes (Oswestry Disability Index [ODI] and visual analog scale [VAS] scores) were similar in both groups and better postoperatively than preoperatively.

Fan et al also found that the cross-sectional area of the multifidus muscle in MRI scanning was significantly lower in the open PLIF than in the minimally invasive PLIF group of patients. ${ }^{48}$ The postoperative ODI and VAS scores were lower in patients who underwent minimally invasive PLIF than open surgery PLIF. However, there are reports showing no benefits of minimally invasive techniques regarding the postoperative atrophy of the multifidus muscle on MRI scans as well as the clinical outcomes.

Arts et al conducted a double-blind randomized study on patients with lumbar disk herniation, comparing tubular diskectomy and conventional microdiskectomy in aspects of creatine phosphokinase (CPK) 1 and CPK2 serum concentrations, atrophy of the multifidus muscle by measuring CSA on the MRI, and clinical outcomes measured with the VAS scale. ${ }^{49}$ There were no significant differences in the serum CPK concentration 1 day after the surgery and in atrophy grade 1 year after the surgery between the groups. Postoperative low-back pain improved in both groups; however, the improvement at 1 -year follow-up was in favor of conventional microdiskectomy.

In addition to being muscle sparing, minimally disruptive techniques also strive to limit the amount of bony resection, thus limiting the chance of creating postoperative spinal instability. ${ }^{50,51}$ Specifically, disruption of the facet joints combined with loss of the midline interspinous ligament complex, as occurs during traditional laminectomy, can contribute to flexion instability. ${ }^{52-54}$ Efforts to limit such potentially destabilizing surgery have focused on developing ligament-sparing techniques. For instance, unilateral laminotomies in which the spinous processes and corresponding tendinous attachments of the multifidus muscle and the supraspinous/interspinous ligaments are preserved theoretically minimize the chance of developing postoperative instability. Based on finite element analysis, limiting the extent of bony resection can improve spinal stability. Limiting bone and ligament removal resulted in greater preservation of normal motion in the lumbar spine..$^{55}$

As an example of MIS technique, we present a patient who underwent minimally invasive TLIF with an expandable cage at the L4-L5 level and subsequent percutaneous posterior spinal fixation with pedicle screws (-Figs. 2-6).

According to the American Association of Neurological Surgeons, MIS can be divided into percutaneous, endoscopic, and minimal access. ${ }^{56}$ The vast majority of literature concerning injuries to muscles describe minimal access procedures or percutaneous screws insertion.

Considering MIS in the context of its less disruptive influence on paraspinal muscles, other features of MIS are worthy of mention. These include a reported reduction of postoperative pain, blood loss, and recovery time. ${ }^{36,37,57}$

Limited exposure and visualization frequently associated with MIS raise the question about possible incomplete decompression of neural structures. To our knowledge, no studies have directly assessed the adequacy of MIS decompression; however, clinical outcome and reoperation rates can be considered indirect markers of adequate decompression. ${ }^{58}$ However, worse short-term clinical results in MIS diskectomy compared with microdiskectomy or open diskectomy were described by Rasouli et al in a Cochrane review. ${ }^{37}$ 


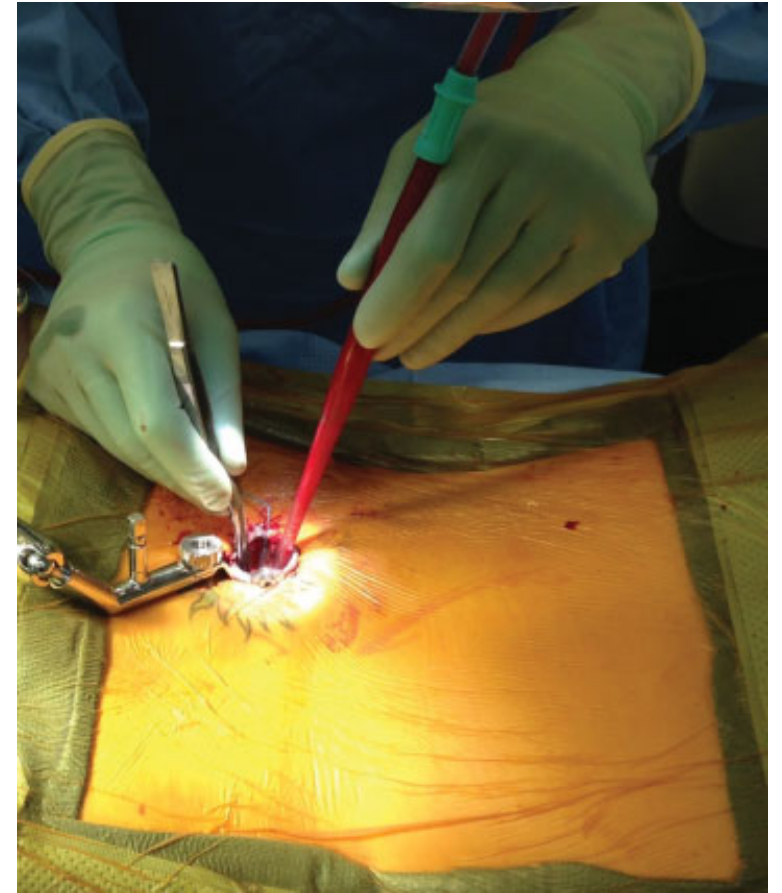

Fig. 2 Minimally invasive transforaminal lumbar interbody fusion with expandible cage with surgeon operating through a tube expander.

However, in long-term follow-up, large sample research and meta-analysis revealed equivalent long-term outcome in both MIS and open surgery groups. ${ }^{38-40,58-61}$

Infection rates associated with MIS are reported to be lower than those reported for open surgery. Ee at al described a 5.77 times lower infection rate in MIS TLIF, laminectomy, and diskectomy when compared with open surgery. ${ }^{62}$ Parker et al performed a cumulative calculation of reported infection incidence from 10 MIS-TLIF and 20 open-TLIF cohorts and described the surgical site infection rate as $0.6 \%$ for MIS versus $4.0 \%$ for open TLIF. ${ }^{63}$

Another concern of MIS interbody procedures related with small exposure is obtaining a successful fusion. Meta-analysis of fusion rates in MIS TLIF versus open surgery found the

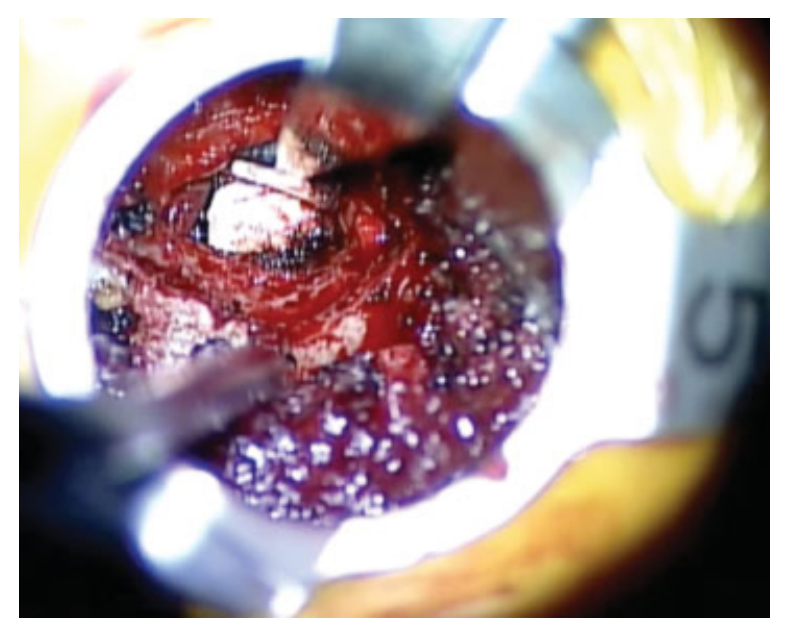

Fig. 3 View of the intervertebral disk through the tube.

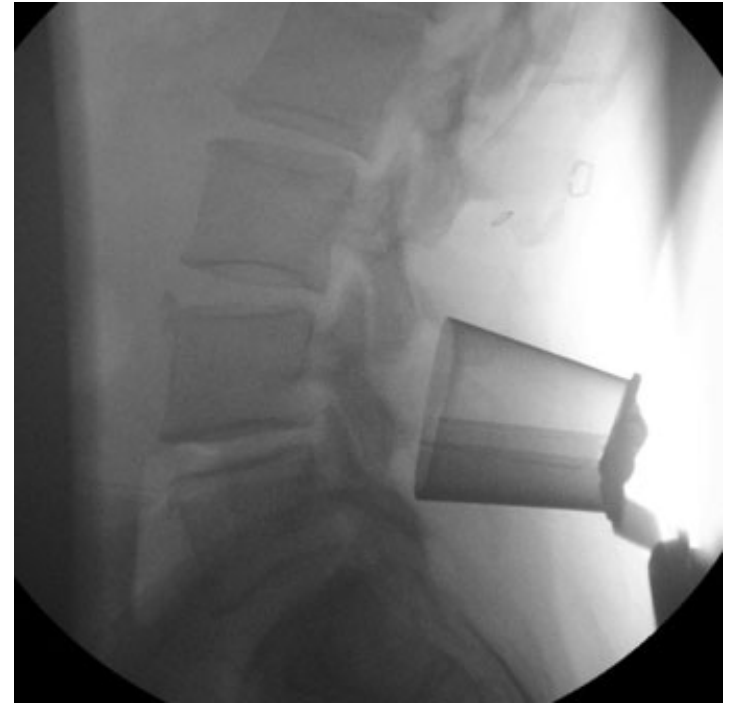

Fig. 4 Intraoperative $X$-ray: tube expander placed in proper position at the $L 4-L 5$ level.

fusion rates to be $94.8 \%$ versus $90.9 \%$, respectively ${ }^{64}$ However, bone morphogenetic protein 2 was much more commonly used in the reported MIS TLIFs. ${ }^{64}$

Among the typical intraoperative complications of MIS, dural tear, neural injuries, malposition of implants, guidewire fracture, or nonunion can be listed. ${ }^{38,40}$ Incidental durotomies and nerve root injuries were more commonly reported in patients undergoing minimal invasive diskectomy with total complication rate at a similar level. ${ }^{38,65}$ Published data regarding complications rate vary; however, in comprehensive reviews and meta-analyses they are comparable ${ }^{59,66}$ or even lower in MIS fusion. ${ }^{39}$ When reporting MIS

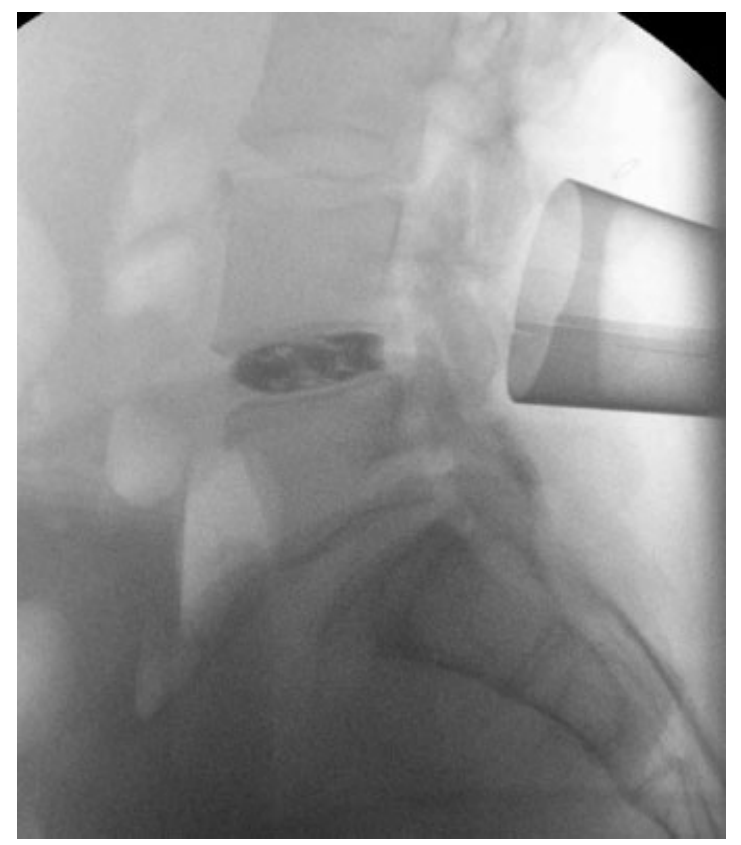

Fig. 5 Intraoperative X-ray: final cage expansion at the L4-L5 level. 


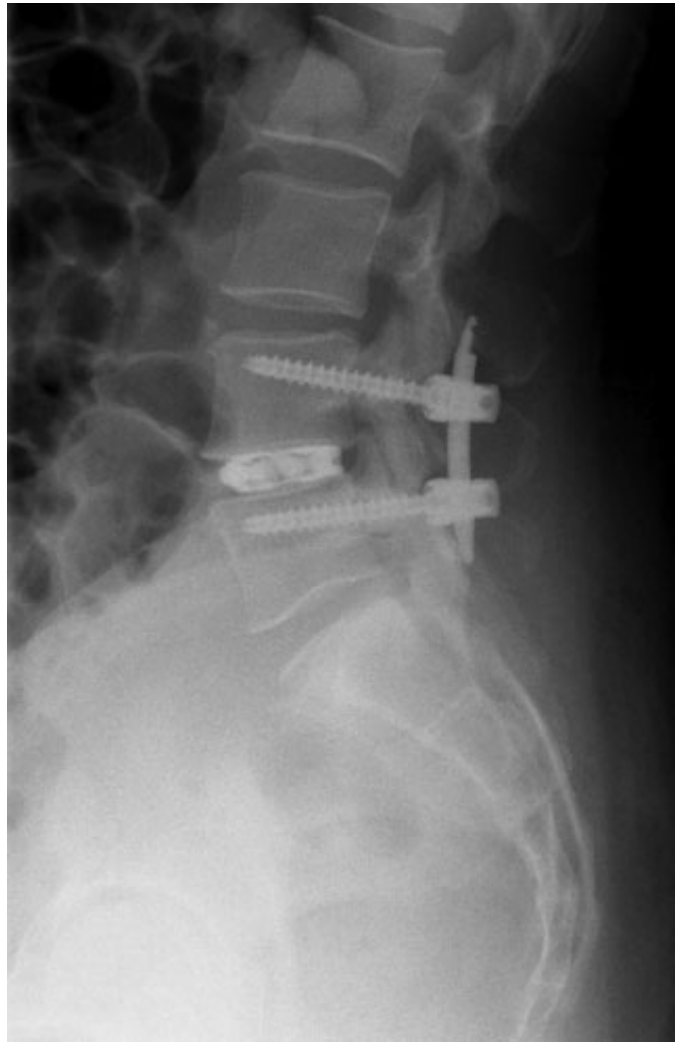

Fig. 6 Intraoperative X-ray: posterior spinal instrumentation with minimally invasive pedicle screws insertion at the $L 4$ and $L 5$ levels.

complications, the learning curve should be taken into consideration. ${ }^{35,40}$

\section{Conclusion}

Minimally disruptive spine surgery aims to minimize surgical morbidity, reduce postoperative recovery time, and improve outcomes. These techniques rely on limiting surgical dissection while safely achieving the goals of decompression and stabilization. As minimally disruptive spine surgery continues to evolve, the risks and benefits of various techniques must be evaluated. Although short-term data are encouraging, longterm prospective randomized studies are necessary to determine whether minimally disruptive approaches offer a significant clinical advantage over traditional open procedures.

\section{References}

1 Ward SR, Kim CW, Eng CM, et al. Architectural analysis and intraoperative measurements demonstrate the unique design of the multifidus muscle for lumbar spine stability. J Bone Joint Surg Am 2009;91(1):176-185

2 Donisch EW, Basmajian JV. Electromyography of deep back muscles in man. Am J Anat 1972;133(1):25-36

3 Cholewicki J, Panjabi MM, Khachatryan A. Stabilizing function of trunk flexor-extensor muscles around a neutral spine posture. Spine 1997;22(19):2207-2212

4 Hu ZJ, Fang XQ Fan SW. Iatrogenic injury to the erector spinae during posterior lumbar spine surgery: underlying anatomical considerations, preventable root causes, and surgical tips and tricks. Eur J Orthop Surg Traumatol 2014;24(2):127-135
5 Stark H, Fröber R, Schilling N. Intramuscular architecture of the autochthonous back muscles in humans. J Anat 2013;222(2): 214-222

6 D'hooge R, Cagnie B, Crombez G, Vanderstraeten G, Achten E, Danneels L. Lumbar muscle dysfunction during remission of unilateral recurrent nonspecific low-back pain: evaluation with muscle functional MRI. Clin J Pain 2013;29(3):187-194

7 Liu X, Yuan S, Tian Y. Modified unilateral laminotomy for bilateral decompression for lumbar spinal stenosis: technical note. Spine 2013;38(12):E732-E737

8 Fortin M, Macedo LG. Multifidus and paraspinal muscle group cross-sectional areas of patients with low back pain and control patients: a systematic review with a focus on blinding. Phys Ther 2013;93(7):873-888

9 Macintosh JE, Valencia F, Bogduk N, Munro RR. The morphology of the human lumbar multifidus. Clin Biomech (Bristol, Avon) 1986; 1(4):196-204

10 Jemmett RS, Macdonald DA, Agur AM. Anatomical relationships between selected segmental muscles of the lumbar spine in the context of multi-planar segmental motion: a preliminary investigation. Man Ther 2004;9(4):203-210

11 Danneels LA. Clinical anatomy of the lumbar multifidus. In: Vleeming A, Mooney V, Stoeckart R, eds. Movement, Stability and Lumbopelvic Pain Integration of Research and Therapy. Philadelphia, PA: Elsevier, Churchill Livingstone; 2007:85-94

12 Macintosh JE, Bogduk N. 1987 Volvo award in basic science. The morphology of the lumbar erector spinae. Spine 1987;12(7): 658-668

13 Macintosh JE, Bogduk N. The attachments of the lumbar erector spinae. Spine 1991;16(7):783-792

14 Bustami FM. A new description of the lumbar erector spinae muscle in man. J Anat 1986;144:81-91

15 Delp SL, Suryanarayanan S, Murray WM, Uhlir J, Triolo RJ. Architecture of the rectus abdominis, quadratus lumborum, and erector spinae. J Biomech 2001;34(3):371-375

16 Gejo R, Kawaguchi Y, Kondoh T, et al. Magnetic resonance imaging and histologic evidence of postoperative back muscle injury in rats. Spine 2000;25(8):941-946

17 Gille O, Jolivet E, Dousset V, et al. Erector spinae muscle changes on magnetic resonance imaging following lumbar surgery through a posterior approach. Spine 2007;32(11):1236-1241

18 Gejo R, Matsui H, Kawaguchi Y, Ishihara H, Tsuji H. Serial changes in trunk muscle performance after posterior lumbar surgery. Spine 1999;24(10):1023-1028

19 Datta G, Gnanalingham KK, Peterson D, et al. Back pain and disability after lumbar laminectomy: is there a relationship to muscle retraction? Neurosurgery 2004;54(6):1413-1420; discussion 1420

20 Hyun SJ, Kim YB, Kim YS, et al. Postoperative changes in paraspinal muscle volume: comparison between paramedian interfascial and midline approaches for lumbar fusion. J Korean Med Sci 2007; 22(4):646-651

21 Kawaguchi Y, Matsui H, Gejo R, Tsuji H. Preventive measures of back muscle injury after posterior lumbar spine surgery in rats. Spine 1998;23(21):2282-2287; discussion 2288

22 Mayer TG, Vanharanta H, Gatchel RJ, et al. Comparison of CT scan muscle measurements and isokinetic trunk strength in postoperative patients. Spine 1989;14(1):33-36

23 Motosuneya T, Asazuma T, Tsuji T, Watanabe H, Nakayama Y, Nemoto K. Postoperative change of the cross-sectional area of back musculature after 5 surgical procedures as assessed by magnetic resonance imaging. J Spinal Disord Tech 2006;19(5):318-322

24 Rantanen J, Hurme M, Falck B, et al. The lumbar multifidus muscle five years after surgery for a lumbar intervertebral disc herniation. Spine 1993;18(5):568-574

25 Granata KP, Marras WS. An EMG-assisted model of loads on the lumbar spine during asymmetric trunk extensions. J Biomech 1993;26(12):1429-1438 
26 Marras WS, Davis KG, Granata KP. Trunk muscle activities during asymmetric twisting motions. J Electromyogr Kinesiol 1998;8(4): 247-256

27 Ren G, Eiskjaer S, Kaspersen J, Christensen FB, Rasmussen S. Microdialysis of paraspinal muscle in healthy volunteers and patients underwent posterior lumbar fusion surgery. Eur Spine J 2009;18(11):1604-1609

$28 \mathrm{Kim} \mathrm{KT}$, Lee SH, Suk KS, Bae SC. The quantitative analysis of tissue injury markers after mini-open lumbar fusion. Spine 2006;31(6): 712-716

29 Mattila M, Hurme M, Alaranta $\mathrm{H}$, et al. The multifidus muscle in patients with lumbar disc herniation. A histochemical and morphometric analysis of intraoperative biopsies. Spine 1986;11(7): 732-738

30 Kawaguchi Y, Matsui H, Tsuji H. Back muscle injury after posterior lumbar spine surgery. Part 1: Histologic and histochemical analyses in rats. Spine 1994;19(22):2590-2597

31 Kawaguchi Y, Matsui H, Tsuji H. Back muscle injury after posterior lumbar spine surgery. Part 2: Histologic and histochemical analyses in humans. Spine 1994;19(22):2598-2602

32 Kawaguchi Y, Yabuki S, Styf J, et al. Back muscle injury after posterior lumbar spine surgery. Topographic evaluation of intramuscular pressure and blood flow in the porcine back muscle during surgery. Spine 1996;21(22):2683-2688

33 Taylor H, McGregor AH, Medhi-Zadeh S, et al. The impact of selfretaining retractors on the paraspinal muscles during posterior spinal surgery. Spine 2002;27(24):2758-2762

34 Styf JR, Willén J. The effects of external compression by three different retractors on pressure in the erector spine muscles during and after posterior lumbar spine surgery in humans. Spine 1998;23(3):354-358

$35 \mathrm{Kim}$ CW. Scientific basis of minimally invasive spine surgery: prevention of multifidus muscle injury during posterior lumbar surgery. Spine 2010;35(26, Suppl):S281-S286

36 Lee GW, Jang SJ, Shin SM, Jang JH, Kim JD. Clinical and radiological outcomes following microscopic decompression utilizing tubular retractor or conventional microscopic decompression in lumbar spinal stenosis with a minimum of 10-year follow-up. Eur J Orthop Surg Traumatol 2014;24(Suppl 1):S145-S151

37 Rasouli MR, Rahimi-Movaghar V, Shokraneh F, Moradi-Lakeh M, Chou R. Minimally invasive discectomy versus microdiscectomy/ open discectomy for symptomatic lumbar disc herniation. Cochrane Database Syst Rev 2014;9:CD010328

38 Dasenbrock HH, Juraschek SP, Schultz LR, et al. The efficacy of minimally invasive discectomy compared with open discectomy: a meta-analysis of prospective randomized controlled trials. J Neurosurg Spine 2012;16(5):452-462

39 Goldstein CL, Macwan K, Sundararajan K, Rampersaud YR. Comparative outcomes of minimally invasive surgery for posterior lumbar fusion: a systematic review. Clin Orthop Relat Res 2014; 472(6):1727-1737

40 Sclafani JA, Kim CW. Complications associated with the initial learning curve of minimally invasive spine surgery: a systematic review. Clin Orthop Relat Res 2014;472(6):1711-1717

41 Bogduk N. The innervation of the lumbar spine. Spine 1983;8(3): 286-293

42 Regev GJ, Lee YP, Taylor WR, Garfin SR, Kim CW. Nerve injury to the posterior rami medial branch during the insertion of pedicle screws: comparison of mini-open versus percutaneous pedicle screw insertion techniques. Spine 2009;34(11):1239-1242

43 Sihvonen T, Herno A, Paljärvi L, Airaksinen O, Partanen J, Tapaninaho A. Local denervation atrophy of paraspinal muscles in postoperative failed back syndrome. Spine 1993;18(5):575-581

44 Kim DY, Lee SH, Chung SK, Lee HY. Comparison of multifidus muscle atrophy and trunk extension muscle strength: percutaneous versus open pedicle screw fixation. Spine 2005;30(1): 123-129
45 Stevens KJ, Spenciner DB, Griffiths KL, et al. Comparison of minimally invasive and conventional open posterolaterallumbar fusion using magnetic resonance imaging and retraction pressure studies. J Spinal Disord Tech 2006;19(2): 77-86

46 Tsutsumimoto T, Shimogata M, Ohta H, Misawa H. Mini-open versus conventional open posterior lumbar interbody fusion for the treatment of lumbar degenerative spondylolisthesis: comparison of paraspinal muscle damage and slip reduction. Spine 2009; 34(18):1923-1928

47 Wang HL, Lü FZ, Jiang JY, Ma X, Xia XL, Wang LX. Minimally invasive lumbar interbody fusion via MAST Quadrant retractor versus open surgery: a prospective randomized clinical trial. Chin Med J (Engl) 2011;124(23):3868-3874

48 Fan SW, Hu ZJ, Fang XQ, Zhao FD, Huang Y, Yu HJ. Comparison of paraspinal muscle injury in one-level lumbar posterior inter-body fusion: modified minimally invasive and traditional open approaches. Orthop Surg 2010;2(3):194-200

49 Arts M, Brand R, van der Kallen B, Lycklama à Nijeholt G, Peul W. Does minimally invasive lumbar disc surgery result in less muscle injury than conventional surgery? A randomized controlled trial. Eur Spine J 2011;20(1):51-57

50 Zander T, Rohlmann A, Klöckner C, Bergmann G. Influence of graded facetectomy and laminectomy on spinal biomechanics. Eur Spine J 2003;12(4):427-434

51 Abumi K, Panjabi MM, Kramer KM, Duranceau J, Oxland T, Crisco JJ. Biomechanical evaluation of lumbar spinal stability after graded facetectomies. Spine 1990;15(11):1142-1147

52 Tuite GF, Stern JD, Doran SE, et al. Outcome after laminectomy for lumbar spinal stenosis. Part I: Clinical correlations. [published correction appears in J Neurosurg 1995;82(5):912]. J Neurosurg 1994;81(5):699-706

53 Tuite GF, Doran SE, Stern JD, et al. Outcome after laminectomy for lumbar spinal stenosis. Part II: Radiographic changes and clinical correlations. J Neurosurg 1994;81(5):707-715

54 Johnsson KE, Willner S, Johnsson K. Postoperative instability after decompression for lumbar spinal stenosis. Spine 1986;11(2): 107-110

55 Bresnahan L, Ogden AT, Natarajan RN, Fessler RG. A biomechanical evaluation of graded posterior element removal for treatment of lumbar stenosis: comparison of a minimally invasive approach with two standard laminectomy techniques. Spine 2009;34(1): $17-23$

56 O'Toole JE. The future of minimally invasive spine surgery. Neurosurgery 2013;60(Suppl 1):13-19

57 Zairi F, Arikat A, Allaoui M, Assaker R. Transforaminal lumbar interbody fusion: comparison between open and mini-open approaches with two years follow-up. J Neurol Surg A Cent Eur Neurosurg 2013;74(3):131-135

58 Wu X, Zhuang S, Mao Z, Chen H. Microendoscopic discectomy for lumbar disc herniation: surgical technique and outcome in 873 consecutive cases. Spine 2006;31(23):2689-2694

59 Sidhu GS, Henkelman E, Vaccaro AR, et al. Minimally invasive versus open posterior lumbar interbody fusion: a systematic review. Clin Orthop Relat Res 2014;472(6):1792-1799

60 Yadav YR, Parihar V, Namdev H, Agarwal M, Bhatele PR. Endoscopic interlaminar management of lumbar disc disease. J Neurol Surg A Cent Eur Neurosurg 2013;74(2):77-81

61 Nomura K, Yoshida M, Kawai M, Okada M, Nakao S. A novel microendoscopically assisted approach for the treatment of recurrent lumbar disc herniation: transosseous discectomy surgery. J Neurol Surg A Cent Eur Neurosurg 2014;75(3): 183-188

62 Ee WW, Lau WL, Yeo W, Von Bing Y, Yue WM. Does minimally invasive surgery have a lower risk of surgical site infections compared with open spinal surgery? Clin Orthop Relat Res 2014;472(6):1718-1724 
332 Pathophysiology of Minimally Invasive Surgery Siemionow et al.

63 Parker SL, Adogwa O, Witham TF, Aaronson OS, Cheng J, McGirt MJ. Post-operative infection after minimally invasive versus open transforaminal lumbar interbody fusion (TLIF): literature review and cost analysis. Minim Invasive Neurosurg 2011;54(1):33-37

$64 \mathrm{Wu}$ RH, Fraser JF, Härtl R. Minimal access versus open transforaminal lumbar interbody fusion: meta-analysis of fusion rates. Spine 2010;35(26):2273-2281
65 Senker W, Meznik C, Avian A, Berghold A. The frequency of accidental dural tears in minimally invasive spinal fusion techniques. J Neurol Surg A Cent Eur Neurosurg 2013;74(6):373-377

66 Fourney DR, Dettori JR, Norvell DC, Dekutoski MB. Does minimal access tubular assisted spine surgery increase or decrease complications in spinal decompression or fusion? Spine 2010;35(9, Suppl):S57-S65 